\title{
Tonal Hierarchies in the Music of North India
}

\author{
Mary A. Castellano \\ Cornell University
}

\author{
J. J. Bharucha \\ Dartmouth College
}

\author{
Carol L. Krumhansl \\ Cornell University
}

\begin{abstract}
SUMMARY
Cross-culturally, most music is tonal in the sense that one particular tone, called the tonic, provides a focus around which the other tones are organized. The specific organizational structures around the tonic show considerable diversity. Previous studies of the perceptual response to Western tonal music have shown that listeners familiar with this musical tradition have internalized a great deal about its underlying organization. Krumhansl and Shepard (1979) developed a probe tone method for quantifying the perceived hierarchy of stability of tones. When applied to Western tonal contexts, the measured hierarchies were found to be consistent with music-theoretic accounts.

In the present study, the probe tone method was used to quantify the perceived hierarchy of tones of North Indian music. Indian music is tonal and has many features in common with Western music. One of the most significant differences is that the primary means of expressing tonality in Indian music is through melody, whereas in Western music it is through harmony (the use of chords). Indian music is based on a standard set of melodic forms (called rägs), which are themselves built on a large set of scales (thäts). The tones within a räg are thought to be organized in a hierarchy of importance.

Probe tone ratings were given by Indian and Western listeners in the context of 10 North Indian rāgs. These ratings confirmed the predicted hierarchical ordering. Both groups of listeners gave the highest ratings to the tonic and the fifth degree of the scale. These tones are considered by Indian music theorists to be structurally significant, as they are immovable tones around which the scale system is constructed, and they are sounded continuously in the drone. Relatively high ratings were also given to the vādi tone, which is designated for each räg and is given emphasis in the melody. The ratings of both groups of listeners generally reflected the pattern of tone durations in the musical contexts. This result suggests that the distribution of tones in music is a psychologically effective means of conveying the tonal hierarchy to listeners whether they are familiar with the musical tradition. Beyond this, only the Indian listeners were sensitive to the scales (thāts) underlying the rāgs. For Indian listeners, multidimensional scaling of the correlations between the rating profiles recovered the theoretical representation of scales described by theorists of Indian music. Thus, the empirically measured tonal hierarchy induced by the räg contexts generates structure at the level of the underlying scales or thāts, but its internalization apparently requires more extensive experience with music based on that scale system than that provided by the experimental context. There was little evidence that Western listeners assimilated the pitch materials to the major and minor diatonic system of Western music.
\end{abstract}


Music can be described in terms of a number of basic attributes: melody, harmony, rhythm, timbre, and musical form. Across cultures, there are marked differences in the emphasis given to these various dimensions. For example, much of the structural complexity of Western music is rooted in harmony, whereas in the music of North India, the focus of complexity is on melody and rhythm. Ethnomusicologists describe the striking variety of organizational schemes that have developed for each aspect of the structured sound materials of music. One organizational principle found quite generally, however, is tonality. Tonality is the centering of the musical materials around one particular tone, called the tonic or tonal center. The tonic is given emphasis in the music through a variety of means. From a psychological point of view, it functions as a reference point for the set of musical pitches as a whole (Krumhansl, 1979), such that the listener perceives each sounded element in its relation to the tonic. The tonic, thus, plays a central role in the process through which the listener assimilates the sounded elements and derives a sense of the underlying organization.

This general description of tonality applies to most music employing variations in pitch, but the particular manner in which tonality is expressed takes a variety of forms. In traditional Western music, the choice of the tonic implies a particular set of scale pitches, but the primary means of establishing tonality is harmonic, that is, through the use of particular combinations of tones as chords, which may be realized as tones sounded simultaneously or implied by successive tones. Out of this harmonic practice has developed a structural

This research was supported by National Science Foundation Grant BNS-81-03570 to Carol L. Krumhansl, who completed the manuscript as a Fellow at the Center for Advanced Study in the Behavioral Sciences, with support from National Science Foundation Grant BNS-76-22943.

The authors are grateful for the helpful comments of Martin Hatch, Elizabeth Bharucha, Ray Jackendoff, Edward Kessler, Diana Deutsch, W. Jay Dowling, and Fred Lerdahl.

Requests for reprints should be sent to Carol L. Krumhansl, Department of Psychology, Cornell University, Ithaca, New York 14853, or to J. J. Bharucha, Department of Psychology, Dartmouth College, Hanover, New Hampshire 03755 . level that relates the different keys, or tonal centers, to one another. These interkey relationships are musically instantiated as modulations, or changes, between keys within a composition. Music theory provides systematic accounts of interkey distance and the compositional methods for achieving the shift from one tonal center to another (see, e.g., Piston, 1978; Schoenberg, 1954/1969).

Music-theoretic descriptions of Indian music (Jairazbhoy, 1971) also refer to relations between different tonal organizations, represented by a large array of scales, called thāts. (When using Hindi words in this article, a bar over an $a$ indicates that the $a$ is pronounced as in $m a$; an a with no bar is to be pronounced like a $u$ as in cut.) On these thäts are built characteristic clusters of melodic features, called rāgs. A rāg specifies a set of melodic features to be used in a musical performance, features that are thought to embody a unique affective quality. Among these characteristic features are a catch phrase (pakar), and perhaps a typical ascending (āroh) and descending (avroh) line. "A räg does not exist in any precise form . . . but is a complex of latent melodic possibilities"' (Jairazbhoy, 1971, p. 32). Classification systems for the rāgs have included ethnological origins, geographic associations, the time of day the rag is to be performed, the nature and number of tones, and similarities in melodic patterns. The classification system most analogous to the Western system of musical keys, however, is one in which the rägs are ascribed to a system of thāts, or parent scales, which are presumed to bear specific relations to one another.

Unlike traditional Western music, which predominantly employs just two scales, major and minor, Indian music draws its pitch materials from a greatly expanded set of heptatonic scales, called thäts. Explicit representations provided by music theorists, often of a geometrical nature, show the degree of relatedness between these scales (Jairazbhoy, 1971). These relations are not expressed directly in Indian music as modulations, which rarely occur, nor are they derivative of the harmonic functions of chords, which do not appear in Indian music. Yet, Indian music theorists have suggested that rägs might be organized around a system of underlying scales in a way that is analogous to the key relations 
in Western music. We present here an empirical study of the psychological basis for this classification system and consider possible commonalities with the psychological representation of Western tonal organization.

\section{Empirical Studies of Tonal Organization}

A primary motivation for the empirical investigation of the psychological response to music is the development of a systematic description of musical structure that is informed from a psychological point of view and that provides a suitable descriptive framework for music of diverse styles. For the most part, quantitative analysis of musical structure crossculturally has been limited to measurements of tuning systems, that is, the frequencies of the musical pitches. Although such investigations provide a way of comparing certain physical properties, such as interval sizes, they have limited utility as a means of studying perceptual and cognitive factors. An alternative approach is to devise methods for measuring attributes that may be primarily, or perhaps entirely, psychological in character.

A method for assessing the psychological response to one aspect of musical structure, tonal organization, is the probe tone method (Krumhansl \& Kessler, 1982; Krumhansl \& Shepard, 1979). In previous studies, this method has been applied to traditional Western music. The present study extends it to the music of North India. The objective is to quantify the hierarchy of stability or structural significance induced by a tonal context on the set of musical tones. As described by Western music theorists, a tonal context establishes a hierarchical ordering on the set of 12 pitches in each octave. The tone that dominates in the hierarchy is the tonic. Following the tonic in the hierarchy are the other tones that are closely related to the tonic; in Western music, these are the third and fifth tones of the scale, the tones that together with the tonic form the tonic triad chord. The other scale tones occupy the next lower levels of hierarchy, and the nonscale (nondiatonic) tones occupy the lowest levels.

To obtain a quantitative measure of this hierarchy, subjects in the earlier experiments were presented with a context (a scale, tonic triad chord, or chord cadence) that quite un- ambiguously established either a major or minor key. This context was then followed by a single probe tone, 1 of the 12 possible (chromatic) tones in an octave; the listener's task was to rate how well the final probe tone fit with the preceding context in a musical sense. The results recovered the patterns expected from the qualitative music-theoretic account just outlined.

Krumhansl and Kessler (1982) demonstrated that a highly regular and interpretable spatial representation of the relations between keys could be derived from the quantified tonal hierarchy. To obtain a measure of the psychological proximity of any two keys, their respective rating profiles were correlated. High correlations correspond to keys that induce a similar hierarchical ordering on the set of musical tones, indicating a close relation between the two keys. Low correlations correspond to distantly related keys. These correlations, computed for each possible pair of keys, were then analyzed using multidimensional scaling. In the resulting configuration, the points for the 24 major and minor keys were located on the surface of a torus in four dimensions. On this surface, there was one circle of fifths for major keys and one for minor keys; these were aligned to represent the parallel and relative relations between major and minor keys. The results accorded well with music-theoretic descriptions of key structure, containing Schoenberg's (1954/1969) maps of musical keys, in local regions.

Krumhansl and Kessler (1982) also noted that keys closely positioned in the spatial representation share harmonically significant chords. That is, structure at the level of keys or tonal centers reflects the fact that musical chords frequently play roles in more than one key. This raises the possibility that the obtained description of key structure may not be a consequence solely of the information summarized in the quantified tonal hierarchy but may be based wholly or in part on the harmonic functions of chords in Western music. An alternative or additional factor that may contribute to perceived key proximity is the relative frequency of modulations between different keys. Modulations in music occur most frequently between keys that are closely positioned in the spatial representation.

In Western music, these three factors-tonal 
hierarchy, harmonic functions of chords, and modulation frequency-are so closely interrelated that it is difficult to assess their relative contributions. Krumhansl and Kessler (1982) assigned the primary contribution to the tonal hierarchy itself. However, key structure can also be derived from measures of perceived chord relations (Bharucha \& Krumhansl, 1983; Krumhansl, Bharucha, \& Castellano, 1982; Krumhansl, Bharucha, \& Kessler, 1982). In addition, there are suggestions that key distance may be closely linked to modulations and transpositions, that is, changes of key. Krumhansl and Kessler (1982) showed that modulations between distant keys are more difficult to assimilate than are those between closely related keys. Cuddy, Cohen, and Miller (1979) and Bartlett and Dowling (1980) found effects of key distance on recognition of transposed melodies. Together, these studies point to three interdependent factors as contributing to key structure in traditional Western music. Therefore, Indian music, which lacks both modulations and harmonic chord functions, provides an interesting comparison case in which the contribution of the tonal hierarchy can be assessed independently of the other two factors.

\section{Tonal Hierarchies in Indian Music}

Like traditional Western music, Indian music is organized around a single tone, the tonic, which is called Sa. In practice, different pitches may serve as the tonic, but in most theoretical accounts the tonic is set by convention to be the tone $\mathrm{C}$. Sa (C) serves as the starting point of the scale and is the most stable of the scale tones. The fifth scale tone, $\mathrm{Pa}(\mathrm{G})$, is considered the next most stable (except in the few scales that exclude it). In both Western and Indian music, tones in the melody are usually perceived as anchored to the most stable tones, primarily the tonic. This anchoring is achieved by a variety of means: by using stable tones more frequently than less stable tones, by placing stable tones in metrically strong positions and at beginnings and endings of phrases, by following unstable tones with stable tones in the form of a resolution, and by using tones from established musical scales. In Indian music an additional mechanism, a drone; is used to explicitly anchor the melody line to the tonic. A drone is the continuous sounding of the tonic, $\mathrm{Sa}(\mathrm{C})$, and usually the fifth scale tone, $\mathrm{Pa}(\mathrm{G})$. The only Western counterpart to the drone is the pedal point, a tone held for a long duration, normally in the bass, while other voices carry changing harmonies. Whereas the Western pedal point is typically used for the duration of a few measures or phrases, the Indian drone is present throughout a performance.

Jairazbhoy (1971) asserts that it is the relative dissonance of certain tones with respect to the drone that induces a need for resolution to one of the drone tones or to a tone consonant with the drone. According to Jairazbhoy, this dissonance accounts for both the need to relate each tone independently to the tonic and the need to resolve unstable tones to the stable tones that follow them. The grounding of each tone to the tonic is reflected in the fact that modulation rarely occurs because the original tonic is sounded continuously.

In addition to the degree of consonance, the hierarchy of stability would also be expected to reflect the particular selection of tones that constitutes the scale underlying the musical context. Indian music employs a large set of scales, and the intervals contained in the scales provide a distinctive flavor for the rāgs built on them. In addition, certain rägs deviate from their underlying scale by the addition or deletion of one or more tones, and these deviations in tuning are said to contribute to the unique character of the rāg. The effect of consonance and dissonance may therefore be modified by the contribution of the particular tonal materials employed in the musical context.

For each rāg, two other tones, called the $v \bar{a} d i$ and samvādi, play important roles. Only for a few rāgs are $\mathrm{Sa}(\mathrm{C})$ or $\mathrm{Pa}(\mathrm{G})$ designated as the vãdi or the samvãdi, because the prominence of $\mathrm{Sa}$ and $\mathrm{Pa}$ is common to most rägs, whereas the vādi and samvādi are unique to individual rāgs. There are no clear definitions of these two tones. However, Bhätkhande (cited in Jairazbhoy, 1972, p. 66) defines the vādi as "that note which compared to the other notes in the räg, is sounded most often with clarity," and Danielou (1968, pp. 61-62) describes it as the "predominant note from which all variations begin and on which they end: it is always accentuated and bears long pauses." The samvādi is said to be the second most sounded 
note, assisting the vādi in the creation of a mood. Ideally, the samvādi should be separated from the vàdi by an interval of a fifth. In actuality, the employment of the vādi and samvādi is somewhat ambiguous, and their characteristics are still a matter of debate by music theorists (e.g., Jairazbhoy, 1972).

To summarize, Indian music theory suggests that a number of factors may influence the ordering of tones in the tonal hierarchy. The tonic, which is sounded as the primary drone, would be expected to dominate in this hierarchy. A relatively high position may also be expected to be given to the secondary drone, which is usually the fifth tone of the scale. The designated vādi and samvādi may also be perceived as prominent compared with the remaining scale tones. Finally, the set of tones in the underlying scale would be expected to hold generally higher positions in the hierarchy than the tones not in the scale.

\section{Circle of Thäts}

The term thāt refers to the scales, each consisting of seven tones, on which rāgs are built. The names of the seven degrees of the that (Sa, $\mathrm{Re}, \mathrm{Ga}, \mathrm{Ma}, \mathrm{Pa}$, Dha, Ni) bear an exact correspondence to the Solfège syllables (Do, $\mathrm{Re}, \mathrm{Mi}, \mathrm{Fa}, \mathrm{Sol}, \mathrm{La}, \mathrm{Ti}$ ), in that they stand for the notes of the major diatonic scale. One thāt, Bilaval, is identical to the major scale. In other thāts, one or more of the scale degrees is flat or sharp, that is, raised or lowered by a half step. $\mathrm{Sa}(\mathrm{C})$ and $\mathrm{Pa}(\mathrm{G})$, the first and fifth scale degrees, are considered immovable and are never altered in any of the scales. The remaining five thāt tones may be altered, each in one direction only. $\mathrm{Re}(\mathrm{D}), \mathrm{Ga}(\mathrm{E})$, Dha (A), and $\mathrm{Ni}$ (B) may be lowered by a half step, and $\mathrm{Ma}(\mathrm{F})$ may be raised by a half step. The altered scale degrees are denoted $\operatorname{Re} b, \mathrm{Ga} b$, Ma\#, Dha $b$, and Ni $b$, respectively. Any combination of the five movable tones may be used, giving rise to a set of 32 possible seven-tone scales. In South Indian music, fewer restrictions are placed on the pitch direction in which the movable tones may be altered, giving rise to 72 scales, of which the 32 North Indian scales are a subset.

Although these 32 scales provide the framework for the classification of all rāgs in North Indian music, Bhātkhande (cited in Jairaz-

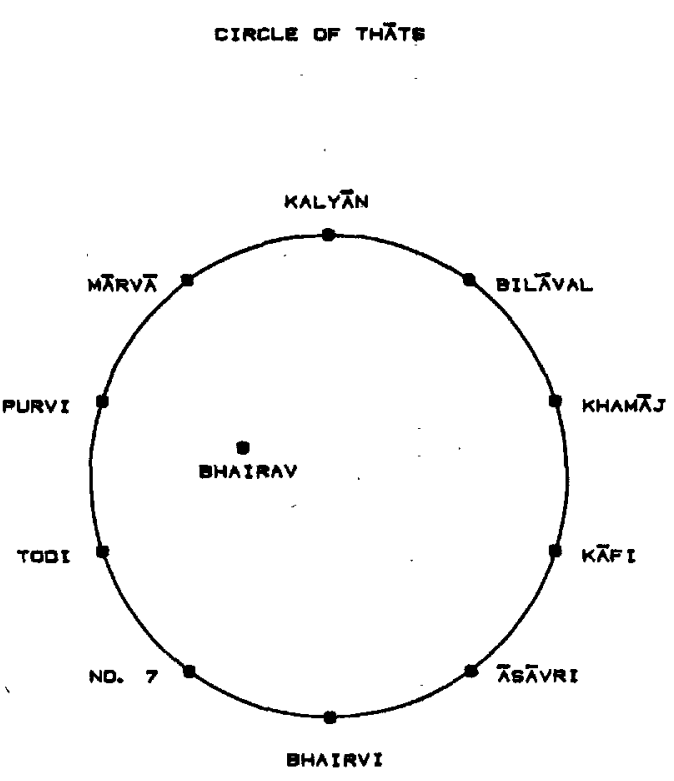

Figure 1. The circle of thāts illustrating inter-thāt distance. (Nine of the 10 thāts on the circle are members of Bhātkhande's classification system. No. 7 is not currently used in North Indian music. Thāt Bhairav occupies a position inside the circle.)

bhoy, 1971) classifies nearly all the raggs under 10 of the 32 thats. Nine of these thats fall on what is called the circle of thats, shown in Figure 1. The tones contained in the thāts are shown in musical notation in Figure 2 and are designated by their letter names in Table 1. Although there are 10 thäts around this circle, 1 (No. 7) is not currently used. The 10th that in Bhātkhande's system of classification is Bhairav, which, as is shown in Figure 1, occupies a position inside the circle of thāts. On the circle, each thāt shares all but one tone with its neighboring thäts. In this respect, the circle of thats is similar to the circle of fifths, which expresses the relations among the major keys and among the minor keys in Western music. It should be emphasized, however, that the circle of thats represents the relations among scales that all have the same tonic tone, unlike the circle of fifths in which the scale of each key is based on a different tonic. Moreover, certain thāts consist of a set of tones not shared by any major or minor Western scale.

Figure 2 illustrates a theoretical account given by Jairazbhoy (1971) for the circle of thāts. This account examines the thäts for the presence of an augmented fourth (an interval 


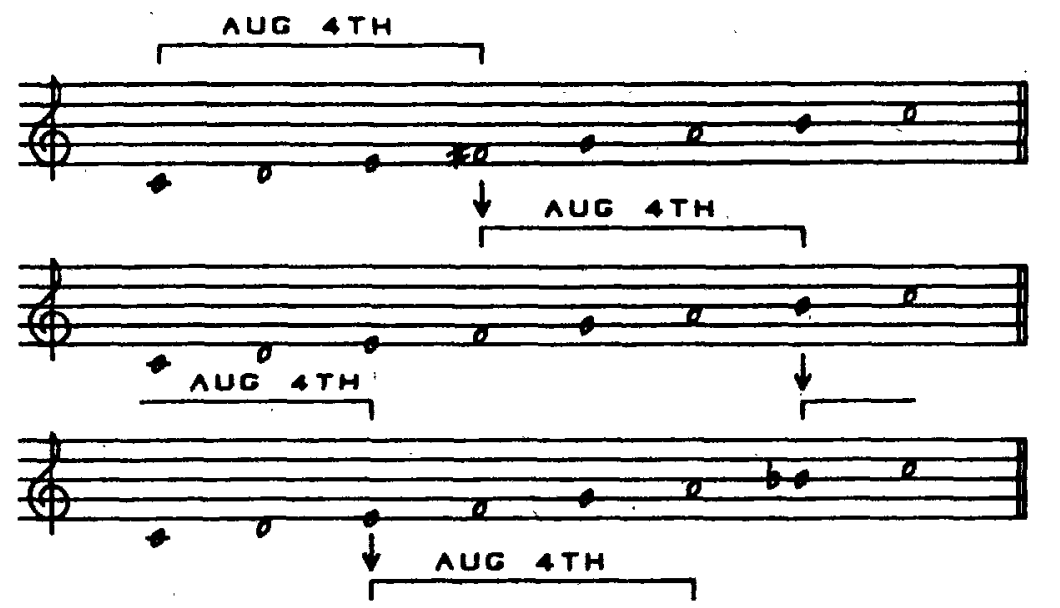

KALYÃN

A 1

o ILÃVal

$\wedge 2$

KHAMÃJ

A 3

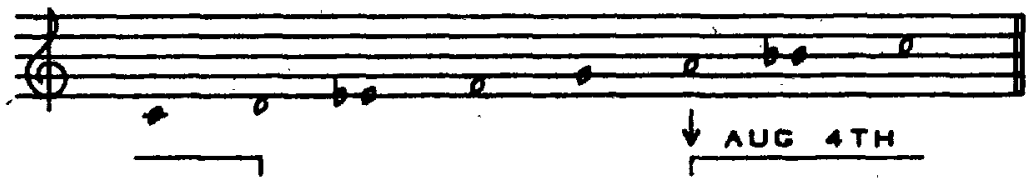

KAFI

$A 4$

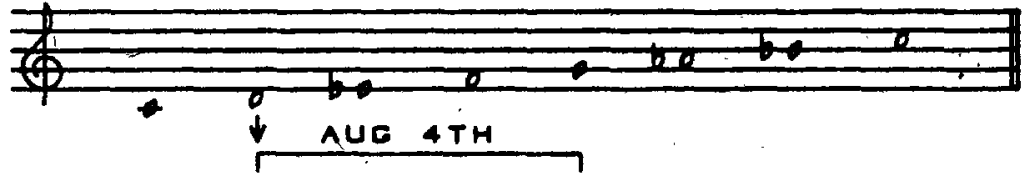

AsÃVR

A 5

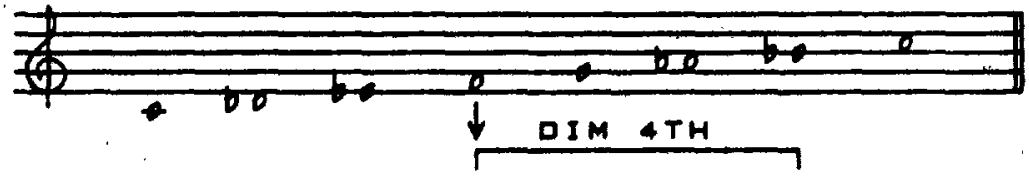

BHAIRVI

A E

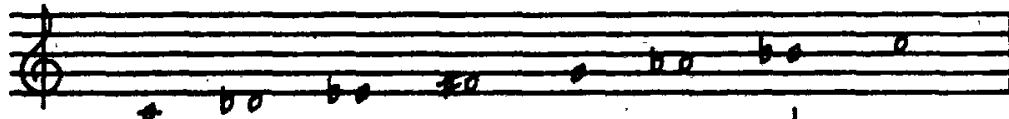

A 7
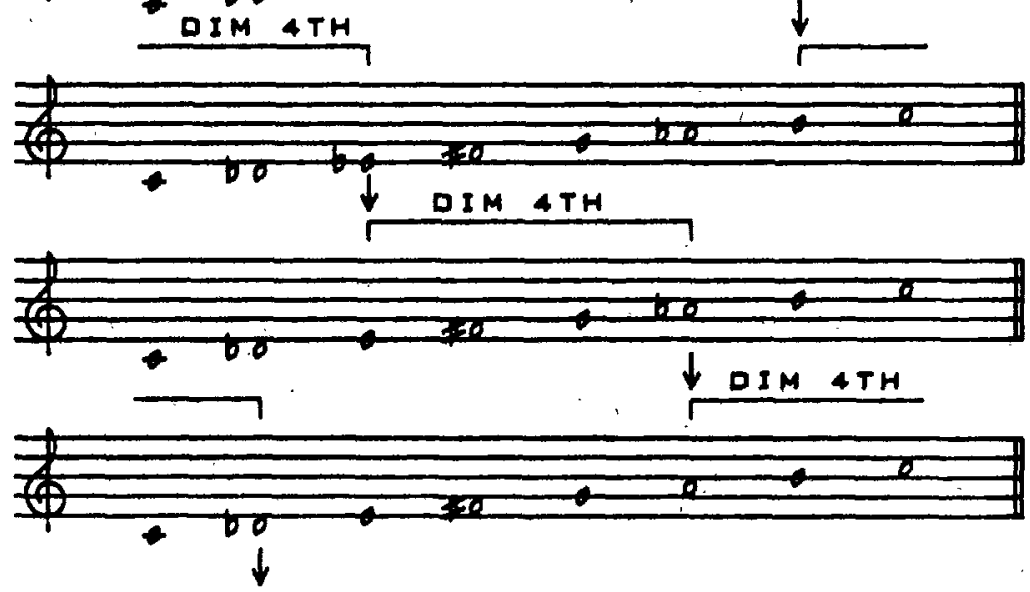

TODI

A $\mathrm{E}$

PURVI

A 0

$M \bar{A} R \vee \bar{A}$

A 10

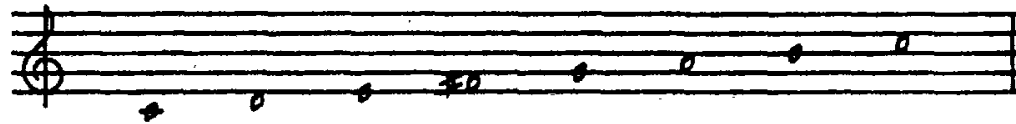

KALYAN

A 1

Figure 2. Jairazbhoy's theoretical model for the circle of thāts based on a systematic progression formed by "correcting" the diminished or augmented fourths of thats. 
Table 1

Rägs Used in the Experiment

\begin{tabular}{|c|c|c|c|c|c|}
\hline Rāg & Parent thāt & Thāt tones & Vādi & Samvādi & Tuning \\
\hline Bhairav & Bhairav & $(C, D b, E, F, G, A b, B)$ & $\mathrm{Ab}$ & Db & Same as thāt \\
\hline Yaman & Kalyān & (C, D, E, F\#, G, A, B) & $\mathrm{E}$ & B & Same as thāt \\
\hline Bilāval & Biläval & $(\mathrm{C}, \mathrm{D}, \mathrm{E}, \mathrm{F}, \mathrm{G}, \mathrm{A}, \mathrm{B})$ & $A$ & $\mathrm{E}$ & B missing \\
\hline Khamāj & Khamāj & $(\mathrm{C}, \mathrm{D}, \mathrm{E}, \mathrm{F}, \mathrm{G}, \mathrm{A}, \mathrm{B} b)$ & $\mathbf{E}$ & $\overline{\mathbf{B}}$ & $B$ added \\
\hline Kāfi & Käfi & $(\mathrm{C}, \mathrm{D}, \mathrm{E} b, \mathbf{F}, \mathbf{G}, \mathrm{A}, \mathrm{B} b)$ & $\bar{G}$ & $\mathrm{C}$ & Same as thāt \\
\hline Āsävri & Bhairvi & $\left(\mathrm{C}, \mathbf{D} b, \mathbf{E} b, \mathbf{F}, \mathbf{G}, \mathbf{A}_{b}, \mathbf{B} b\right)$ & A & Db & Same as thāt \\
\hline Bhairvi & Bhairvi & $(\mathrm{C}, \mathrm{D} b, \mathrm{E} b, \mathrm{~F}, \mathrm{G}, \mathrm{A} b, \mathrm{~B} b)$ & $\mathrm{C}$ & $\mathbf{F}$ & $\mathrm{D}$ and $\mathrm{F} \#$ added \\
\hline Todi & Todi & (C, Db, Eb, F\#, G, Ab, B) & $\mathrm{A}_{b}$ & $\mathbf{E}$ & Same as thät \\
\hline Purvi & Mārvā & $(\mathrm{C}, \mathrm{D} b, \mathrm{E}, \mathrm{F} \#, \mathrm{G}, \mathrm{A}, \mathrm{B})$ & $\mathrm{E}$ & $\mathbf{B}$ & $F$ added \\
\hline Mārvā & Mārvā & $(\mathrm{C}, \mathrm{D} b, \mathrm{E}, \mathrm{F \#}, \mathbf{G}, \mathrm{A}, \mathrm{B})$ & $\mathbf{E}$ & A & G missing \\
\hline
\end{tabular}

of three whole steps formed by four successive scale tones) or a diminished fourth (an interval of two whole steps formed by four successive scale tones). For example, in the Kalyān thāt, there is one augmented fourth formed by Sa (C) and Ma\# (F\#). If one "corrects" this augmented fourth by lowering the Ma\# by a half step to $\mathrm{Ma}(\mathrm{F})$, one obtains the next that, $\mathrm{Bi}$ lavval, around the circle. However, this introduces another augmented fourth between $\mathrm{Ma}$ (F) and $\mathrm{Ni}(\mathrm{B})$ that, when altered, produces the next that around the circle. This process continues to account for the succession of thāts until the Bhairvi thāt is reached. At this point, the process cannot be continued further, because this would mean lowering $\mathrm{Pa}(\mathrm{G})$ a half step, which would violate the fundamental premise that $\mathbf{P a}$ is immovable, that is, that it cannot be raised or lowered. The enharmonically equivalent tone, Ma\# (F\#), is introduced instead, giving the that labeled A7 (not in current usage). However, this introduces a diminished fourth between $\mathrm{Ma \#}(\mathrm{F \#})$ and $\mathrm{Ni}$ b $(B)$, which is corrected in the next step around the circle by raising the $\mathrm{Nib}(\mathrm{B} b)$ to $\mathrm{Ni}(\mathrm{B})$, giving the Todi thāt. This in turn introduces a diminished fourth between $\mathrm{Ni}(\mathrm{B})$ and $\mathrm{Ga} b$ $(\mathrm{E} b)$, which is then changed to $\mathrm{Ga}(\mathrm{E})$, giving the next thāt, Purvi. This process of successively raising the upper tone of the diminished fourth continues until finally the first thāt, Kalyān, is reached.

This theoretical account generates the circular configuration called the circle of thats, which plays a central role in Bhätkhande's classification system of rāgs. The circle of thāts shares certain structural features with the circle of fifths, namely that successive scales overlap in all but one scale pitch. Indeed, thāts Kalyān through Bhairvi correspond in their scale pitches to the Western keys of $G, C, F, B$, $\mathrm{E} b$, and $\mathrm{A} b$ major, respectively. They differ, however, in that the Indian thats are all based on a fixed tonic, $\mathrm{Sa}(\mathrm{C})$, whereas each major key has a different tonic. The remaining thats, A7 through Mārvä, do not correspond to the set of scale pitches of any major or minor key in that they contain distinctively different component intervals.

\section{North Indian Rāgs}

The concept of a rāg has no counterpart in Western music. There exist several hundred rāgs, with distinctive melodic figures. Thus, a räg is characterized not only by its scale but also by the manner in which it combines the tones. Jairazbhoy $(1971$, p. 28$)$ describes a rāg as the "melodic basis for composition and improvisation." Music-theoretic descriptions of Indian music refer extensively to the emotional content of rāgs and even assign qualities to the individual tones out of which they are constructed. Although our present focus is on factors governing pitch organization, considerable weight is given in Indian music theory to the affective dimension also (Bose, 1960; Danielou, 1968; Jairazbhoy, 1971; Kaufmann, 1968; Neuman, 1980).

A musical performance consists of the expression of a rāg set to a particular metric pattern (tāl). A musical performance typically begins with an exposition of the characteristic melodic features of the rāg, the specific delivery of which is improvised by the performer. This exposition, called the àläp, is metrically free, 
seeming to consolidate the rāg before the tāl is introduced by the drummer. When the tal is first introduced, following the alapp, the melodic line usually follows a set composition (gat) that is based on the räg. As soon as the tâl is consolidated, the performer may depart from the set composition, using it only as a basis for improvisation. The set composition generally has at least two sections, the sthāyi and the antra $\bar{a}$. The sthayyi is played mostly in the lower and middle pitch registers and often focuses on the vādi, whereas the antrā is played in the middle and upper pitch registers and often focuses on the samvádi.

\section{Experimental Design}

Ten North Indian rāgs in common usage were chosen as stimulus materials for the experiment. Table 1 presents the names of the rāgs and their underlying thāts, vādis, samvădis, and tunings (notes added or deleted from the thāts) as given by Danielou (1968). These 10 rägs are classified under eight of the parent thāts. It should be noted that some of the rāgs have names that do not correspond to the names of the underlying thāts. In certain cases the name of the ràg is the same as the name of some other thāt. This may reflect inconsistencies in the classification scheme, historical changes, or geographical differences. In any case, we adopt Danielou's (1968) classification. To facilitate interpretation of the results presented later, Figure 3 shows the 10 rāgs employed in the study arranged according to the presumed relations among the designated underlying scales.

The block of trials for each rāg began with the sounding of the sthäyi section of the fixed composition played twice to establish the rag. Each experimental trial began with a brief theme (roop), which incorporates the characteristic features of the composition and therefore of the rāg on which it is based. Figure 4 shows in musical notation the sthayi and theme from rāg Yaman (Danielou, 1968). Musical examples can be heard on the record accompanying Jairazbhoy (1971) and other recordings of classical North Indian music. Using the probe tone method, the theme context on each experimental trial was followed by a single pitch, 1 of the 12 tones in an octave range. The listener was asked to rate how well
RĀGS ON THE CIRCLE OF THĀTS

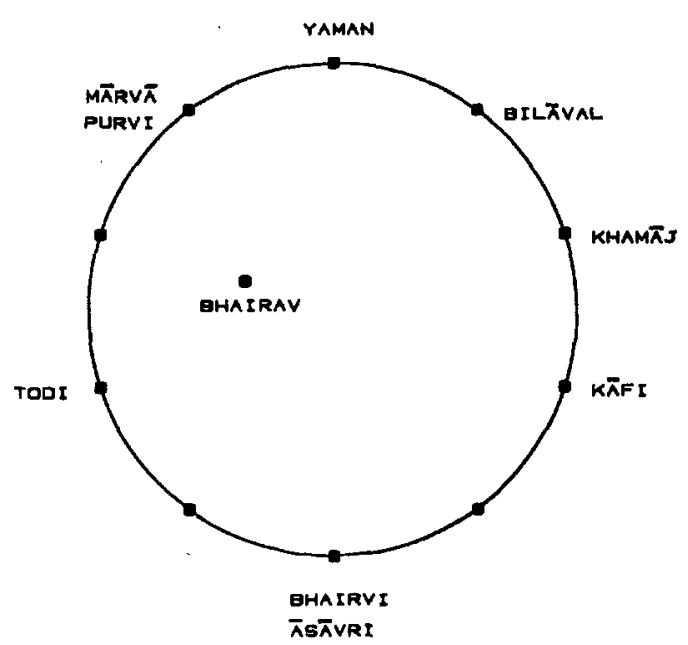

Figure 3. The 10 rags used in the experiment placed on the circle of thatts. (Each rāg is located in the position of its parent thāt.)

the final tone fit with the preceding context in a musical sense. The listeners were divided into two groups based on their experience with Indian music.

\section{Method}

Subjects. Sixteen subjects were offered $\$ 4$ for participating in one experimental session lasting $2 \mathrm{hr}$. There were two groups of 8 subjects. One group consisted of listeners with considerable exposure to Indian music, 6 of whom were recruited from the India Student Association. Subjects in this group had been exposed to North Indian classical music, beginning at an average age of 12 years old. Six played an Indian instrument, averaging 4 years of formal training. The 8 subjects listened to Indian music for an average of $3 \mathrm{hr}$ per week and listened to Western music for an average of $10 \mathrm{hr}$ per week. Subjects in the other group had minimal exposure to and no formal instruction in Indian music. Seven of these subjects played a Western instrument, averaging 6 years of formal training. These 8 subjects listened to Western music $18 \mathrm{hr}$ per week. Only 1 of these listeners reported having listened to Indian music.

Apparatus. The stimuli were synthesized digitally by a DMX-1000 (Digital Music Systems, Inc.) signal-processing computer under the control of a PDP-11/24 computer. Recordings were made on Maxell UD 35-90 tapes using a Sony TC-388-4 tape recorder. The tapes were played at 7 in. per s (19 cm per s) through an Ampex AA-620 loudspeaker at approximately $65 \mathrm{~dB}$ sound pressure level. 
Stimulus materials. Equal tempered tuning, based on an $\mathrm{A}(4)$ of $440 \mathrm{~Hz}$, was used. Each tone consisted of a fundamental and six higher harmonics with the following amplitude ratios: $1,1 / 3,1,1 / 3,1,1 / 3,1$. The amplitude envelope consisted of a 10 -ms onset gradient followed by a linear decay to zero, thus simulating a plucked instrument such as the sarod. Frequency modulation (Chowning, 1973) was used to simulate the sound of the $C$ and $G$ drone tones, with a ratio of 7:5 between modulator and carrier frequencies and a modulation index of 10 (Digital Music Systems, Inc., 1981).

The sthāyi and theme for each rāg were taken from Danielou (1968). There were 10 blocks of trials, each representing 1 of the 10 rägs shown in Table 1. Each block of trials began with two successive presentations of the sthāyi. The duration of the sthāyis averaged $65.75 \mathrm{~s}$, with a range of $37.80-93.03 \mathrm{~s}$. Following the sthãyi, subjects were presented with 14 experimental trials. Each trial consisted of a theme, followed by a 1-s pause, and then followed by a probe tone that was sounded for $1 \mathrm{~s}$. The duration of the themes averaged $19.44 \mathrm{~s}$, ranging from $10.80 \mathrm{~s}$ to
$39.36 \mathrm{~s}$. The same theme was used for the block of 14 consecutive trials. The first 2 trials of each block were for practice. In the other 12 trials, the 12 probe tones from the chromatic scale were paired with the theme in random order. The drone, consisting of the $\mathrm{Sa}(\mathrm{C})$ and $\mathrm{Pa}(\mathrm{G})$, was sounded during the sthāyi and theme but not during the probe tone: A 5-s interval between trials allowed subjects to record their responses. Blocks were presented in different random orders to different subjects.

Procedure. Subjects were instructed to judge how well each probe tone fit with the preceding theme in a musical sense. The ratings were made on a 7-point scale ranging from fits poorly (1) to fits well (7). Responses were indicated by circling the appropriate number on the response sheet.

\section{Results}

Rating profiles. The listeners rated each of the 12 tones of the chromatic scale in the context of each of the 10 rägs listed in Table 1.

\section{YAMAN}

\section{STHĀYI}

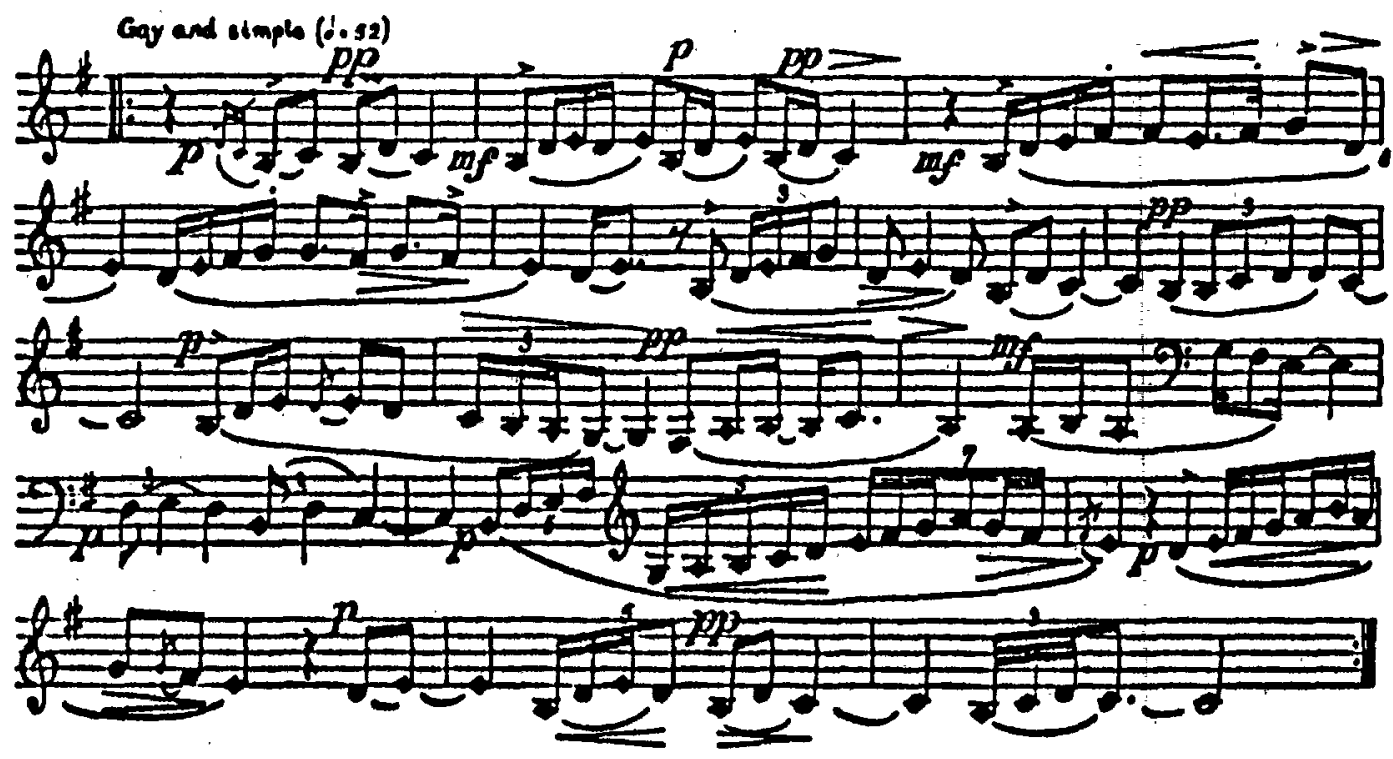

THRME

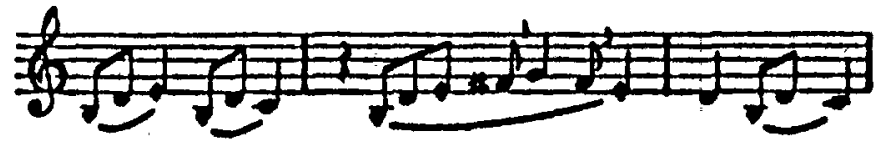

Figure 4. Musical transcription of the sthāyi and theme (roop) of rāg Yaman. 
This produced rating profiles for the 10 rāgs, which are plotted in Figure 5, averaged over all 16 subjects. The profiles for Indian and Western listeners were quite similar; for individual rāgs, the intergroup correlations averaged .871 and were significant $(p<.01)$ for each of the 10 ragss. Consequently, the profiles shown in Figure 5 are those for the two groups combined. Differences between the two groups are described later.

Tonal hierarchies. A number of statistical tests were performed to determine whether the ratings from the experiment conformed to the predicted tonal hierarchy. The series of tests can best be described with respect to Figure 6 , where each branch corresponds to a test performed. The figure shows the average rating given to the tones in each of the following sets: non-thāt tones, thāt tones, $\mathrm{Sa}(\mathrm{C}), \mathrm{Pa}(\mathrm{G})$, vādi, samvādi, and the remaining thāt tones. In these analyses, the ratings given to the tones in each set were computed for each subject, averaged over the 10 rāg contexts. The first test compared the ratings for thāt and non-thāt tones, finding a significant preference for thāt over non-thāt tones, $F(1,15)=129.16, p<.01$. The non-thāt tones were then eliminated, and the next analysis compared $\mathrm{Sa}(\mathrm{C})$ with the other thāt tones, showing a preference for Sa (C), the tonic, over the other that tones, $F(1$, $15)=39.30, p<.01$. Sa (C) was then eliminated and the next test showed a significant preference for $\mathrm{Pa}(\mathrm{G})$ over the remaining thät tones, $F(1,15)=42.97, p<.01$. After $\mathrm{Pa}(\mathrm{G})$ was eliminated, the next analysis showed a significant preference for the vādi over the remaining tones, $F(1,15)=18.41, p<.01$. However, once the vâdi was eliminated, no
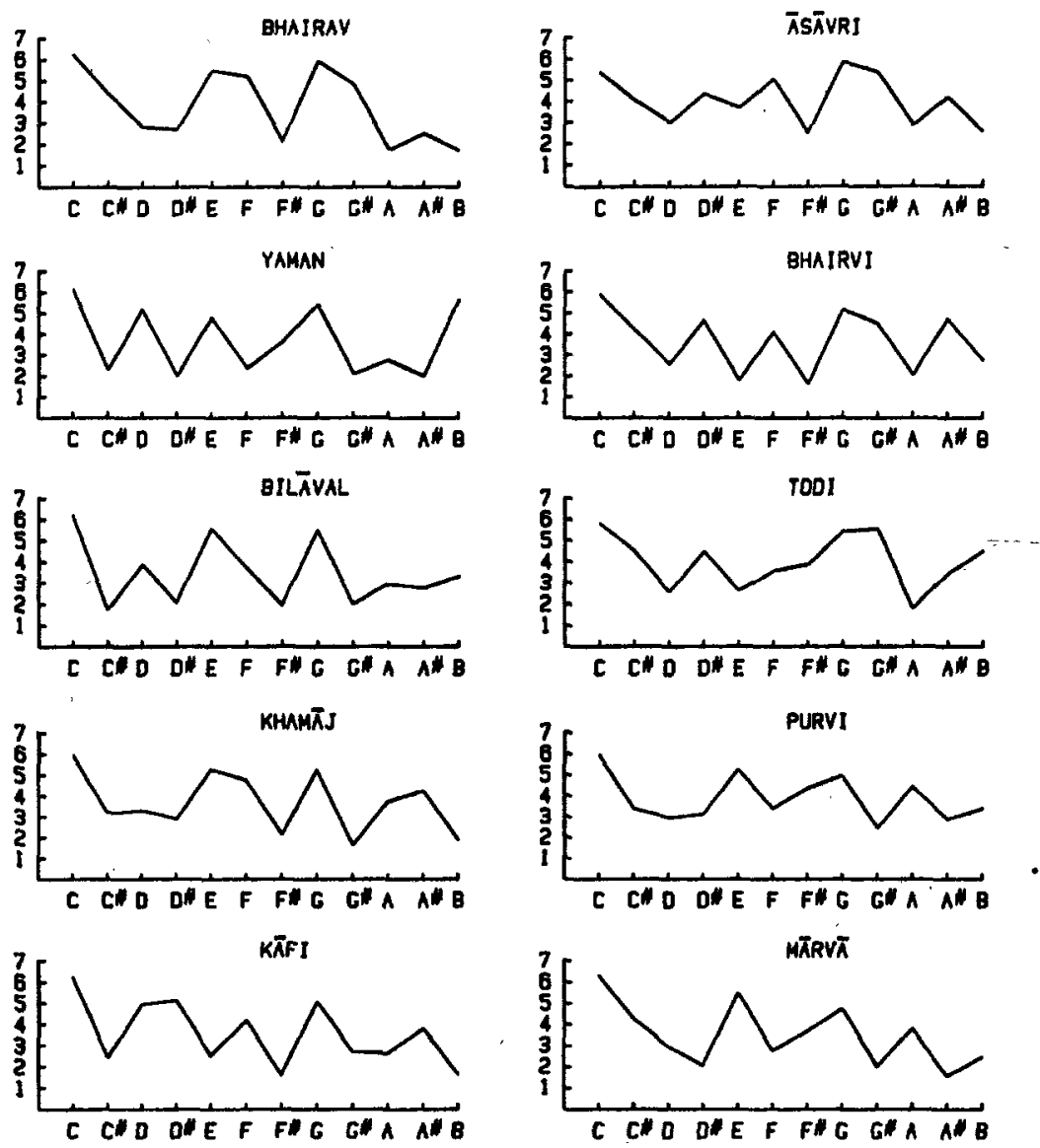

Figure 5. The obtained rating profiles for 10 rägs. (Each profile consists of the ratings, averaged over 16 subjects, given to the 12 chromatic scale tones in the context of each of the rägs.) 
preference was found for the samvādi over the remaining thāt tones. It should be noted that the tests for vādi and samvādi eliminated the data for those rāgs in which either was Sa (C) or $\mathrm{Pa}(\mathrm{G})$.

The same series of tests was performed separately for the Indian and Western subjects, with virtually identical levels of statistical significance. The results of all listeners generally conformed to the predicted tonal hierarchy. There was a definite preference for thāt tones over non-thāt tones, and within the set of thāt tones, $\mathrm{Sa}(\mathrm{C}), \mathrm{Pa}(\mathrm{G})$, and the vādi received particularly high ratings.
Tone duration. In order to assess the extent to which the rating given to a tone is a function of the relative amount of time the tone is sounded in the rāg context compared with other tones, the duration of each of the 12 chromatic tones in each rāg theme was tabulated. The durations of the 2 tones in the drone were not included in this measure. These duration values were correlated with the rating profiles. The correlations for the 10 rägs averaged .820 , and all were significant $(p<.01)$. The same analysis performed separately for Indian and Western listeners showed no difference between the two groups; for Indian

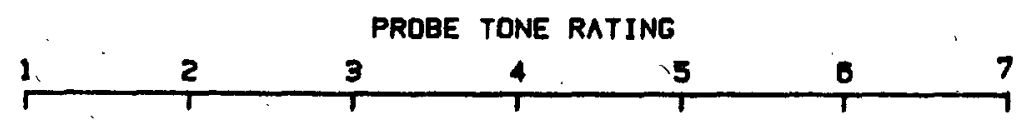

ALL 12 TONES

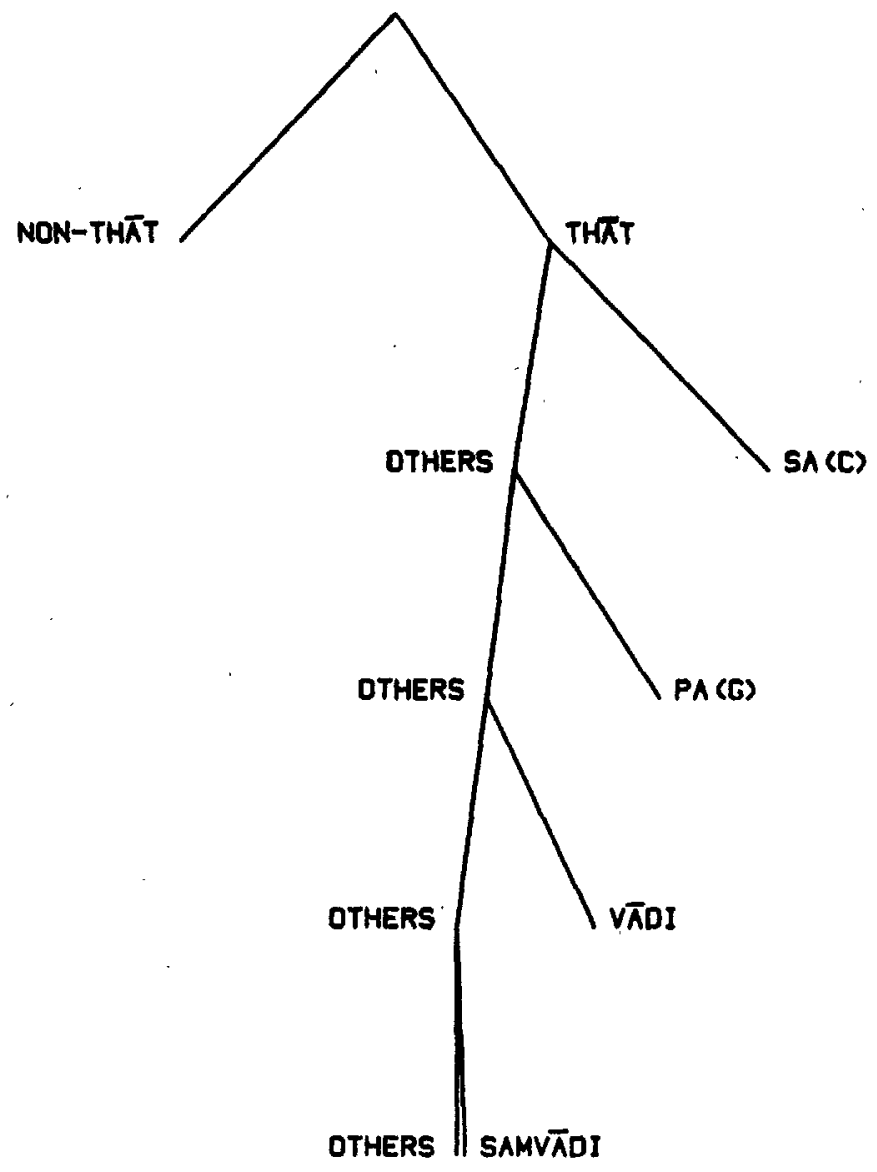

Figure 6. Tree diagram to illustrate the hierarchical ordering imposed by the rāg contexts: (Each branch shows the average rating given to a tone or to a set of tones.) 
listeners, the average correlation was .828 ; for Western listeners, .805.

Thät membership. In order to evaluate the effect of whether the probe tone is a member of the parent thāt of the rāg, a variable representing thät membership was constructed. Each probe tone was scored 1 if it was contained in the parent thāt of the rāg, and 0 if it was not. These values were correlated with the rating profiles from the experiment. The correlations averaged .821 for the 10 rāgs, and all were significant $(p<.01)$. The strength of the effect of thāt membership, however, differed for the two groups of subjects. Thāt membership had a stronger and more consistent effect for the Indian listeners, with an average correlation of .832 between the thāt membership variable and the rating profiles; the corresponding average was .740 for the Western listeners, and these two values differed significantly, $F(1,9)=6.40, p<.05$. Thus, the ratings of the Indian listeners reflected more strongly whether the probe tone was contained in the parent thāt of the rāg than did the ratings of the Western listeners.

Tone duration and thät membership. The previous analyses showed that higher ratings were generally given to tones that are sounded for relatively long durations in the rāg theme and tones that are in the parent that of the rāg. These variables are, of course, related; tones heard in the theme are for the most part members of the underlying thāt. An analysis of the tone duration and thāt membership variables showed these variables correlated with each other. The average correlation over the 10 thants was .691 , and in all cases, the correlation was significant $(p<.05)$. However, these variables are not identical, so a multiple correlation was performed to assess their relative contributions. This multiple correlation predicts the rating profile for each rāg from the two variables, tone duration and thāt membership.

For all 16 subjects, the average multiple $R=$ $.905, p<.01$, with both tone duration and thāt membership contributing to the multiple correlation. The $t(9)$ values for the regression weights averaged 2.84 and 2.40 for tone duration and thät membership, respectively (both $p s<.05$ ). However, when the same analysis was performed separately for Indian and Western listeners, differences were found. For
Indian listeners, the average multiple $R=.907$, and significant contributions to the regressions were made by both tone duration, $t(9)=2.76$, $p<.05$, and thāt membership, $t(9)=2.73$, $p<.05$. In contrast, the average multiple correlation for Western listeners was somewhat lower, $R=.857$, and although the tone durations contributed significantly, $t(9)=2.37$, $p<.05$, thāt membership did not, $t(9)=1.70$, $n s$. Thus, tone duration and thät membership together accounted quite well for the patterns found in the rating profiles of the Indian listeners. For Western listeners, the ratings related systematically to the pattern of the tone durations but not to thāt membership.

Effect of tuning. In five of the ràgs, the tuning (i.e., the actual set of tones used in the rāg) differs from its parent thāt by the addition or deletion of one or two tones. For example, rāg Bilāval is missing $\mathrm{Ni}(\mathrm{B})$, even though it is included in its parent thät, Bilāval. All together, six tones differ between the tuning of the rāg and its underlying thāt. In five of the six cases, the Indian listeners' ratings corresponded more accurately to the tuning than did the ratings of the Western listeners. If the tuning included a tone absent from the that, the Indian listeners gave the tone a higher rating than did the Western listeners; conversely, if the tuning omitted a tone contained in the thāt, the Indian listeners gave it a lower rating than did the Western listeners. This indicates that the Indian listeners were more sensitive to deviations in the rāg tuning from the parent thāt than were the Western listeners.

Major and minor key profiles. To assess the similarity of the rating profiles for the rāgs to those for major and minor keys, the present results were compared with the profiles for major and minor Western diatonic scales from our earlier experiment (Krumhansl \& Kessler, 1982). The $C$ major and $C$ minor profiles were used because these keys share the same tonic as the räg contexts of the present experiment. Using the average data for all 16 subjects, the profile for each rāg was correlated with both major and minor key contexts of the earlier experiment. The correlations with $\mathrm{C}$ major averaged .616 and varied considerably. The highest correlation, .934, was with räg Bilāval, whose parent scale is identical to $\mathrm{C}$ major; the lowest correlation, .181, was with rāg Todi. The correlations with $\mathrm{C}$ minor averaged .489 ; 
the highest correlation with any of the rāg profiles, .842, was the Käfi, the tones of which are included in (the various forms of) the $\mathrm{C}$ minor scale; the lowest correlation, .249, was with the rāg Purvi. The same analysis performed separately for Indian and Western listeners showed similar patterns; the correlations with major keys (averaging .587 and .609 for Indian and Western listeners, respectively) and with minor keys (averaging .456 and .499 for Indian and Western listeners, respectively) showed a very slight but nonsignificant tendency for the responses of Western listeners to produce ratings more like Western major and minor keys.

Because of the strong commonalities between Western and Indian rating profiles, the analysis just presented may not be optimal for uncovering differences between the groups as they correspond to major and minor Western keys. A more sensitive test would be to correlate the differences between the ratings for the two groups with the major and minor profiles. When this analysis was performed, the correlations of the differences between Western and Indian ratings with the major key profile averaged .192 across the 10 rags. A $t$ test was performed to see whether these correlations were significantly different from 0 , with the resulting value, $t(9)=4.77, p<.01$. The correlations of the differences with the minor key profile averaged $.219 ; t(9)=5.49, p<.01$. Thus, there was a consistent tendency for the differences between the Western and Indian listeners' ratings to be related to $\mathrm{C}$ major and $\mathrm{C}$ minor. It should be noted, however, that this accounted for only about $4 \%$ of the variance of the difference between the ratings for the two groups.

Inter-rāg correlations. To obtain a measure of similarity between rāgs, their corresponding rating profiles were correlated. If two rāgs are based on parent thāts that have similar tonal hierarchies, the correlation between their rating profiles would be high. Conversely, if two rägs are based on parent thāts with dissimilar tonal hierarchies, the correlation between their rating profiles would be low. Figure 7 (top) shows the rating profiles for rāgs Yaman and Bilāval superimposed. These two rāgs have similar profiles, producing a correlation of .775. Figure 7 (bottom) shows the rating profiles for rāgs Yaman and Bhairvi; their profiles

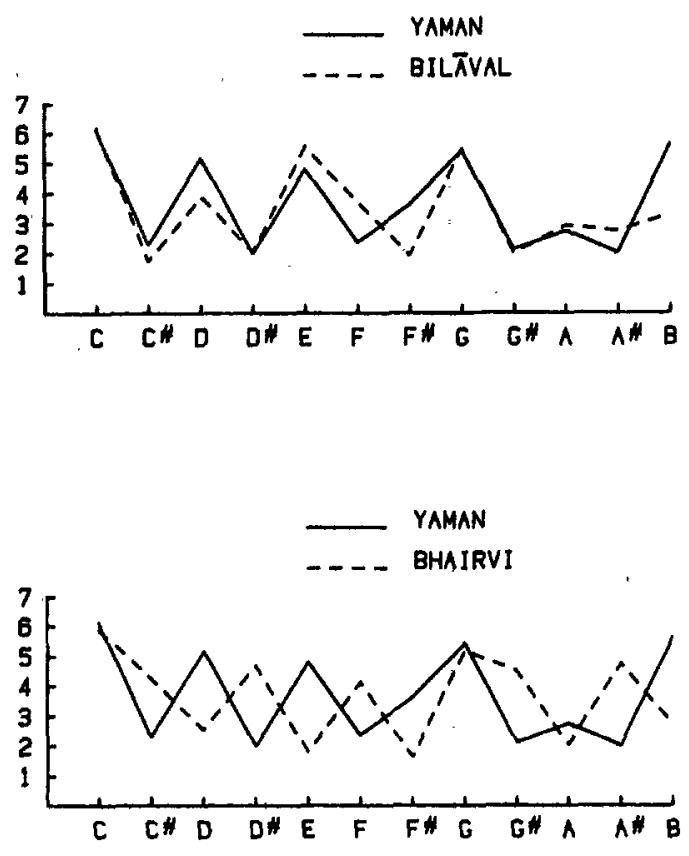

Figure 7. The probe tone ratings for rāg Yaman superimposed onto the ratings for rāg Bilāval (top) and onto the ratings for rāg Bhairvi (bottom) to illustrate relatively similar and dissimilar rating profiles.

are dissimilar, producing a correlation of -.081 . Correlations were computed for all pairs of rāgs for all listeners combined, and were computed separately for the Indian listeners and the Western listeners.

Multidimensional scaling of inter-rāg correlations. The inter-rāg correlations produced a matrix of values indicating the degree of similarity or dissimilarity between each pair of rāgs. These were analyzed using multidimensional scaling (Kruskal, 1964; Shepard, 1962a, 1962b). The particular program used was MDSCAL (Kruskal, 1968). The results for Indian and Western listeners are shown separately, because the differences between the groups were perhaps most apparent in the scaling solutions.

The solution obtained in two dimensions for the Indian listeners, with a stress value of .060 (using Stress Formula 1), is shown at the top of Figure 8. These results showed a marked similarity to the pattern predicted by Jairazbhoy's circle of thāts, with Bhairav located near the center of the configuration and the other rags arranged around the circle in the predicted order. Notice that rāgs Purvi and 
Mārvā, which are both based on the parent thāt Mārvā, are represented by points in virtually identical positions. Similarly, rāgs Āsāvri and Bhairvi, both based on parent thãt Bhairvi, are represented by points in the same location. Two other rāgs, Bilāval and Khamāj, alșo occupy essentially the same position in the scaling solution. This can be understood by considering the tunings of the two rägs. Although they are classified under two different parent

INOIAN SUEJECTS

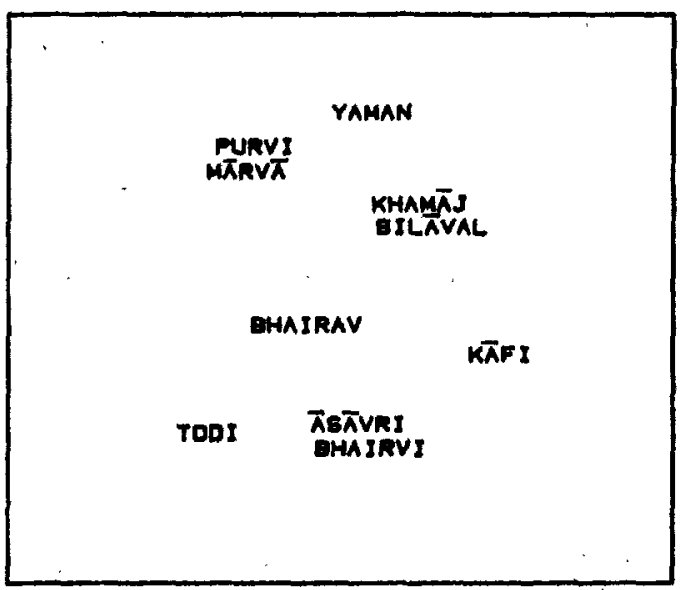

WESTERN SUBJECTS

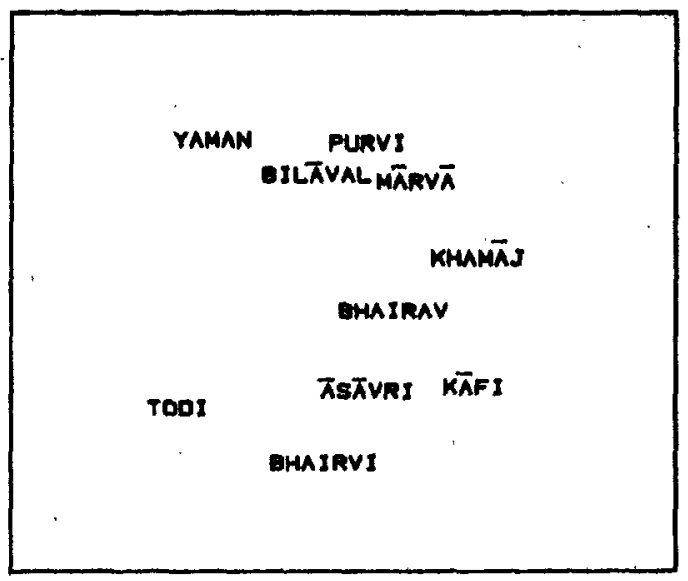

Figure 8. The two-dimensional scaling solution of the intercorrelations between the 10 rāg rating profiles for Indian subjects (top) and for Western subjects (bottom). thāts, their tunings are almost identical. Their common tones are $\mathrm{Sa}(\mathrm{C}), \operatorname{Re}(\mathrm{D}), \mathrm{Ga}(\mathrm{E}), \mathrm{Ma}$ (F), $\mathrm{Pa}(\mathrm{G})$ and Dha (A); they differ only in the seventh degree of the scale. The tuning of Bilãval contains neither Ni (B) nor Nib (Bb), whereas the tuning of Khamaj contains both.

To substantiate the similarity between this scaling solution and the theoretical circle of thāts (Jairazbhoy, 1971) shown in Figure 3, the two spatial configurations were compared using the program CMH2 (Cliff, 1966). This program rotates, translates, and expands or contracts the scaling solution of the data to best fit a specified configuration, in this case the theoretical circle of thāts. The resulting goodness of fit measure was .953 , indicating that the scaling solution of the data from the Indian listeners recovered the predicted circle of thāts to a good degree of approximation.

The two-dimensional scaling solution for the group of Western listeners is shown at the bottom of Figure 8. The stress value was .089. In addition to having a somewhat higher stress value, this solution matched the theoretical circle of thāts less exactly than did that of the Indian listeners. The measure of goodness of fit of this solution to the theoretical circle of thāts was only .650; rāgs Purvi and Mārvā were misplaced with respect to räg Yaman, and rāgs sharing the same parent thät were not spatially identified. Thus, the rating profiles given by Western listeners recovered less well the predicted relations between the thäts underlying the rāgs used in the experiment.

\section{Discussion}

Cross-cultural research in cognition is often motivated by the attempt to classify phenomena as either universal or culturally relative. In few cases can this distinction be established unequivocally, either because of the complex intertwining of innate factors with cognitive structures acquired through experience or for lack of a rigorous methodology for cross-cultural research. There are additional reasons more specific to the present experiment to be cautious of conclusions concerning universality. First, the subjects were presented with musical segments that are rich in information; the responses of both Indian and Western listeners would be expected to reflect to some degree the information readily accessible from 
the particular segments of music heard in the experiment.

Second, certain structural features are shared by Indian and Western music. These shared features, noted in the beginning of this article, include the establishment of a tonic tone as a primary point of reference, the secondary importance of the tone a fifth above the tonic, the approximate equivalence of the tuning systems, and the use of basic scales consisting of seven tones in each octave range. Despite important and theoretically interesting differences between these musical systems, the commonalities would be expected to induce certain similarities in the patterns of responses observed in the experiment.

Third, the Indian listeners who participated were currently residing in the United States and have had considerable exposure to Western music in addition to their training in Indian music. Consequently, their responses might have been influenced to some extent by their experience with Western music. Although the particular selection of Indian listeners might not have been ideal, it should be noted that the influence of Western music is currently quite strong in the popular music of India, and it would be difficult to obtain a subject population totally unfamiliar with Western tonal structure. A more important point in this connection, however, is that music-theoretic descriptions of Indian music provide hypotheses about the pattern of results expected if the listeners are in fact sensitive to the structures of Indian music. The results conform closely to these expectations, and moreover, interpretable differences are found between the results for Indian listeners and those for Western listeners who have had minimal exposure to Indian music.

Thus, the motivation for the present experiment is not to uncover universalities in music perception and cognition. We are, however, concerned with the effect of previous experience with a musical tradition on the listener's response to the musical materials used in the experiment. Comparisons between the two groups of listeners provide information about two questions. The first question is the following: What features of tonal organization become internalized through experience? Tonal organization is expressed in a variety of ways cross-culturally. Certain features of this organization are explicit in the music. Others may require greater exposure if they are to become abstracted and internalized. Patterns contained in the results of Indian listeners above and beyond the patterns contained in the results of the Western listeners would be interpreted as the product of more extended exposure to Indian music.

The second question concerns the description of the experience of a listener unfamiliar with the conventions of a particular musical tradition. For the Western listeners, what structural features of the music are apparent? For listeners trained in Western music but unfamiliar with Indian music, certain organizational principles may be immediately apprehended, either through sensitivity to the patterns contained in the sounded elements or through analogies with the organizational principles of Western music. The responses of the Western listeners, then, can be used to understand the kinds of perceptual processes that a listener who is naive to a particular musical tradition brings to bear on the apprehension of its underlying organization.

Another reason for undertaking the present study was to provide a test of the general applicability of the methods developed and previously applied exclusively to Western music. Cross-cultural comparisons of music are difficult owing to the extremely diverse forms that music takes. Attempts to develop an abstract, descriptive terminology general enough to encompass music of these diverse styles are subject to biases as to which features are to be considered important. Owing to their familiarity with particular traditions, analysts may give undue emphasis to certain features and may ignore others. Moreover, such analyses cannot ensure that the features incorporated in the theoretical system are, in fact, psychologically salient. Although the music may follow certain constraints or conventions, these may not be perceptually or cognitively realized even for a listener familiar with the tradition.

The alternative approach taken here is to employ a methodology that allows us to determine which features are, for the listener, psychologically important. The form that the data take permits the application of certain analytic techniques, facilitating comparisons across different musical systems and across 
different groups of listeners. In addition, in the cases of Western and Indian music, the results map onto a construct described by music theorists, the hierarchy of tonal functions, which serves as a source of validation for the experimental methodology.

Tonal hierarchies: $S a, P a$, and the vādi. Tonal hierarchies described by music theorists are based on careful analyses of the employment of tones within the musical literature. Tones said to dominate in these hierarchies are given emphasis in the music through a variety of means common to Western and Indian music. In Indian music, the special roles of the tonic, Sa (C), and of the fifth degree of the scale, $\mathrm{Pa}(\mathrm{G})$, are also made explicit through their constant sounding in the drone. These tones are also considered significant because they are fixed or immovable; hence, the interval of a perfect fifth above the tonic is a constant feature of most Indian rāgs. In the present experiment, both Indian and Western listeners were sensitive to these structural invariants. The highest rating overall was given to the tonic, and the next highest rating, to the fifth tone of the scale.

Other tones considered structurally significant in North Indian music are the vādi and samvādi. The vādi is given emphasis in the sthāyi, the section played at the beginning of each block of trials in the experiment. As expected, the ratings of both Indian and Western listeners reflected a sensitivity to the special function of this tone; its rating was on the average higher than the other thāt tones exclusive of $\mathrm{Sa}(\mathrm{C})$ and $\mathrm{Pa}(\mathrm{G})$. The samvādi is of secondary importance and is not necessarily featured in the sthāyi. In the experiment, neither group of listeners rated this tone higher than the other thāt tones, on the average. Generally, however, the results confirmed predictions from Indian music theory concerning the tonal hierarchies.

Effect of tone duration. To explore the effect of the relative durations of the musical tones on the probe tone ratings, we correlated these two variables. For each rāg, we computed the total duration of each of the 12 chromatic tones in the theme and correlated these values with the rating profile for that räg. The highly significant correlations indicated a strong effect of tone duration on the listener's judgments; tones given high ratings were sounded for rel- atively long durations in the context. This factor was equally strong for Indian and Western listeners. By employing contexts that are rich in structure, the present study has pointed to tone duration as a dominant factor controlling the perception of tonal hierarchies.

A similar effect of tone duration seems to apply to Western tonal music. Hughes (1977) did a tone duration analysis of one particular tonal composition, Schubert's Opus 94, No. 1. Krumhansl (1982) noted that the relative durations of the tones in this composition correlated almost perfectly with the probe tone ratings (as measured by Krumhansl \& Kessler, 1982) for the predominant key of the composition. This was true even though the musical contexts used to collect the probe tone data did not themselves contain the same distribution of durations. Other evidence for the internalization of the distribution of musical elements comes from a more recent study (Krumhansl, 1983), which investigated the perceived relative significance of chords in major and minor key contexts. These ratings correlate highly with their frequency of use in representative eighteenth and nineteenth century Western compositions as measured by Budge (1943).

These studies together support the notion that the distribution of durations or frequencies of musical elements is a salient determinant of perceived tonal organization. The present study shows that in the case of Indian music, the duration distribution of the tones is an important factor for listeners both familiar and unfamiliar with the musical tradition when the experimental context is itself musically rich. In the case of Western tonal music, this factor appears to be effective for both tones and chords even when the experimental context does not itself reflect the distribution generally found in the musical tradition.

In addition to the relative durations of tones, other features would be expected to contribute to the assimilation of the tonal organization. For example, tones to be heard as stable may appear in positions of rhythmic stress and near the beginning and end of phrases. In addition, the sequential ordering of pitches and the use of tones sounded simultaneously as chords or sounded sequentially to suggest harmonies are important in Western tonal music. A recent 
study by Bharucha (in press) used sequences of tones that were all equal in duration and found evidence of a subordination of nonharmonic tones to chord tones in both rating and memory judgments. The results of that study conform to the theoretical analyses proposed by Schenker (1935/1979) and are found even under conditions in which the duration distributions of the tones do not provide sufficient information to drive this subordination. Thus, factors other than the relative duration of tones contribute to the listener's derivation of a sense of the underlying tonal hierarchy.

Similarity to Western tonal hierarchies. Dowling (1978) and Meyer (1956, p. 63) suggested that Western listeners would assimilate non-Western music to the scale and harmonic structures with which they were familiar. If this were the case, the rating profiles for major and minor keys (Krumhansl \& Kessler, 1982; Krumhansl \& Shepard, 1979) would be expected to correlate more highly with the rating profiles of the Western listeners than with those of the Indian listeners. Although there was a slight tendency for this to be the case, the effect accounted for only a small percentage of the differences between the ratings of Western and Indian listeners. Moreover, the responses of the Western listeners depended very strongly on the particular rāg of the context. For some rāgs, the correlation with major or minor keys was quite high, but in other cases, it was quite low. This was also the case for the ratings of the Indian listeners. Thus, there is little evidence that the Western tonal hierarchies were dominant for either group of listeners. Instead, listeners appeared to base their responses largely on the particular musical materials employed within the context of the experiment, regardless of their relative experience with Indian and Western music. Thus, the results showed considerable sensitivity to the structure made explicit by the contexts used in the experiment.

Indian scale structure and the circle of thats. The factor that did distinguish between Indian and Western listeners was the North Indian scale structure. As noted earlier, the responses of both groups of listeners reflected the relative emphasis explicitly given to the tones in the experimental contexts; beyond this, only the Indian listeners showed sensitivity to the functions of tones in the underlying parent scale (thāt). Although scale membership and the distribution of tone durations within a musical passage are necessarily correlated, they are not identical; in the present experiment, scale membership as distinguished from tone duration appeared as a factor only for the Indian listeners. In addition, the Indian listeners showed greater sensitivity to the cases in which the tuning of a rāg differed from its underlying thāt. Western listeners, although sensitive to many of the structural features described by Indian music theorists and made explicit in the musical contexts, do not appear able to extract from the experimental contexts the designation of certain tones as scale members.

This differential sensitivity of the listeners to scale membership is perhaps brought out most clearly in the multidimensional scaling analysis of the correlations between the rating profiles for the 10 rāgs. For the Indian listeners, the multidimensional scaling solution recovered quite precisely the theoretical relations existing among the thāts underlying the rāgs (Jairazbhoy, 1971), which are based on the overlap of thāt tones. Rāgs based on the same thāt or closely related thats were represented by closely positioned points; rāgs based on distantly related thāts were represented by points that were far apart. As would be expected, given the reduced effect of thāt membership for Western listeners, the scaling of their data contained deviations from the expected pattern.

Thus, the tonal hierarchies measured in this and in previous experiments (Krumhansl \& Kessler, 1982; Krumhansl \& Shepard, 1979) have been shown to give rise to relations at more abstract levels of musical structure. In Western music, these relations are at the level of tonal centers or keys. Interkey distance, although shown by Krumhansl and Kessler (1982) to be derivable from probe tone ratings, might also depend on the harmonic functions of chords in keys or the frequency of modulations between different keys. These factors are inextricably interconnected in Western music, so that their relative contribution to interkey distance cannot be determined unequivocally. Indian music, in contrast, employs neither chords nor modulations, and yet music-theoretic treatments refer to both the ordered structural significance of tones and to the varying degrees of relatedness between 
tonal organizations. The present study indicates that the relations between thāts may be psychologically mediated through tonal hierarchies. In the absence of other factors, the internalization of tonal hierarchies is sufficient to induce the internalization of a more abstract level of musical structure: the relations between different tonal organizations.

\section{General Discussion and Conclusions}

The experiment reported here extended the probe tone method developed by Krumhansl and Shepard (1979) to the music of North India, a musical system with features quite distinct from traditional Western music. The probe tone ratings were strikingly similar for the listeners trained in Indian music and for those trained only in Western music. The results of both groups confirmed several predictions from music theory concerning tonal hierarchies in North Indian music. These results were attributed to the use of relatively complex musical contexts. The tones that dominate in the hierarchy are given emphasis in the contexts in one way or another, being sounded in the drone or for longer durations in the melodies.

Thus, in the present case, there is a convergence between the relative emphasis given to the various elements in the music itself and to their theoretical stability or structural significance. This convergence may be due to the fact that the musical selections used in the experiment establish the melodic materials of the răg. We would expect to see in these sections the exposition of features useful to the listener for achieving an initial sense of the underlying organization. The results suggest that even listeners unfamiliar with Indian music are sensitive to these features.

Once the tonal hierarchy has been established perceptually, the music can elaborate on or deviate from this basic organization. During the improvisatory sections of the rāg, for example, a poorer match would be expected between the explicit emphasis given the various musical elements and the abstract hierarchy of stability that applies to the broader tonal context. A similar divergence would be predicted for the development sections and for sections with modulations or tonal ambiguity in Western music.
Despite the strong commonalities found between the two groups of listeners, Indian listeners showed greater sensitivity to scale (thăt) membership than did Western listeners. Apparently, Western listeners were unable to extract from the musical contexts the Indian scale structure beyond internalizing information about the relative durations of the various tones in the perceptually immediate context. A number of considerations suggest, however, that with somewhat more experience, Western listeners may be able to gain an appreciation of the complex system of scales.

In the present experiment, there was little evidence that the Western listeners assimilated the musical contexts to the Western system of major and minor scales. Thus, the activation of these scale schemata in Western listeners is not obligatory, leaving open the possibility of internalizing quite different scale systems. For these listeners, the probe tone ratings were consistently related to the distribution of tones in the contexts, which in general reflects scale membership. Greater experience with a somewhat wider variety of musical contexts would lead, in principle, to the differentiation between scale and nonscale tones.

Additional evidence that scale structure may be fairly readily abstracted comes from a number of other studies. Krumhansl and Keil (1982) showed that scale structure in Western music is internalized relatively early in the developmental sequence. By the early grades of elementary school, listeners preferred diatonic to nondiatonic tones as completions of short melodies. Hansen, Kessler, and Shepard (1983) found both Western and Balinese listeners to be sensitive to the tonal hierarchies that apply to both Western diatonic and Balinese pelog scales, despite the marked deviations between the tunings of the two systems. For Balinese slendro scales, however, the pattern of results was less clear for all listeners, suggesting possible limitations in the tuning systems that can give rise to perceived tonal hierarchies. Finally, Pollard-Gott (1983) recently showed that, with repeated exposures, even listeners with little musical training are able to gain an appreciation of the similarities between variations of themes despite considerable surface differences among the instances heard.

By using naturalistic musical contexts, the present experiment and that of Pollard-Gott 
(1983) have shown that listeners are remarkably sensitive to organizational features underlying richly structured musical contexts. This suggests that considerable cognitive resources are applied to the problem of abstracting conceptual features from complex musical materials. In the present cross-cultural investigation, we demonstrated that listeners have considerable flexibility in the tonal organizations that can be internalized. Moreover, we identified features of the music itself that appear to promote the internalization of hierarchies of tonal stability, a music-theoretic concept that applies to virtually all musical systems.

\section{References}

Bartlett, J. C., \& Dowling, W. J. (1980). Recognition of transposed melodies: A key-distance effect in developmental perspective. Journal of Experimental Psychology: Human Perception and Performance, 6, 501-515.

Bharucha, J. J. (in press). Anchoring effects in music: The resolution of dissonance. Cognitive Psychology.

Bharucha, J., \& Krumhansl, C. L. (1983). The representation of harmonic structure in music: Hierarchies of stability as a function of context. Cognition, 13, 63102.

Bose, N. K. (1960). Melodic types of Hindustan: A scientific interpretation of the rāga system of Northern India. Bombay: Jaico.

Budge, H. (1943). A study of chord frequencies based on the music of representative composers of the eighteenth and nineteenth centuries. New York: Bureau of Publications, Teachers College, Columbia University.

Chowning; J. M. (1973). The synthesis of complex audio spectra by means of frequency modulation. Journal of the Audio Engineering Society, 21, 526-534.

Cliff, N. (1966). Orthogonal rotation to congruence. Psychometrika, 31, 33-42.

Cuddy, L. L., Cohen, A. J., \& Miller, J. (1979). Melody recognition: The experimental application of musical rules. Canadian Journal of Psychology, 33, 148-157.

Danielou, A. (1968). The rāga-s of Northern Indian music. London: Barrie \& Rockliff.

Digital Music Systems, Inc. (1981). Music-1000 manual. Cambridge, MA: Author.

Dowling, W. J. (1978). Scale and contour: Two components of a theory of memory for melodies. Psychological Review, 85, 341-354.

Hansen, C., Kessler, E. J., \& Shepard, R. N. (1983, November). Music perception here and in Bali: $A$ crosscultural study. Paper presented at the meeting of the Psychonomic Society, San Diego, CA.

Hughes, M. (1977). A quantitative analysis. In M. Yeston (Ed.), Readings in Schenker analysis and other approaches (pp. 144-164). New Haven: Yale University Press.

Jairazbhoy, N. A. (1971). The rägs of North Indian music: Their structure and evolution. London: Faber \& Faber.
Jairazbhoy, N. A. (1972). Factors underlying important notes in North Indian music. Ethnomusicology, 16, 6381.

Kaufmann, W. (1968). The ragas of North India. Bloomington, IN: Indiana University Press.

Krumhansl, C. L. (1979). The psychological representation of musical pitch in a tonal context. Cognitive Psychology, 11, 346-374.

Krumhansl, C. L. (1982, August). A quantitative description of musical key structure. Paper presented at the meeting of the Society for Mathematical Psychology, Princeton, NJ.

Krumhansl, C. L. (1983). [Quantified chord hierarchies in Western tonal music]. Unpublished raw data.

Krumhansl, C. L., Bharucha, J., \& Castellano, M. A. (1982). Key distance effects on perceived harmonic structure in music. Perception \& Psychophysics, 32, 96108.

Krumhansl, C. L., Bharucha, J., \& Kessler, E. J. (1982). Perceived harmonic structure of chords in three related musical keys. Journal of Experimental Psychology: Human Perception and Performance, 8, 24-36.

Krumhansl, C. L., \& Keil, F. C. (1982). Acquisition of the hierarchy of tonal functions in music. Memory \& Cognition, 10, 243-251.

Krumhansl, C. L., \& Kessler, E. J. (1982). Tracing the dynamic changes in perceived tonal organization in a spatial representation of musical keys. Psychological Review, 89, 334-368.

Krumhansl, C. L., \& Shepard, R. N. (1979). Quantification of the hierarchy of tonal functions within a diatonic context. Journal of Experimental Psychology: Human Perception and Performance, 5, 579-594.

Kruskal, J. B. (1964). Nonmetric multidimensional scaling: A numerical method. Psychometrika, 29, 28-42.

Kruskal, J. B, (1968). How to use MDSCAL, a program to do multidimensional scaling and multidimensional unfolding (Version 4). Murray Hill, NJ: Bell Laboratories.

Meyer, L. B. (1956). Emotion and meaning in music. Chicago: University of Chicago Press.

Neuman, D. M. (1980). The life of music in North India. Detroit, MI: Wayne State University Press.

Piston, W. (1978). Harmony (4th ed.). New York: Norton.

Pollard-Gott, L. (1983). Emergence of thematic concepts in repeated listening to music. Cognitive Psychology, 15 , 66-94.

Schenker, H. (1979). Free composition (E. Oster, Ed. and Trans.). New York: Longman. (Original work published 1935)

Schoenberg, A. (1969) Structural functions of harmony ( $\mathrm{L}$. Stein, Ed.). New York: Norton. (Original work published 1954)

Shepard, R. N. (1962a). The analysis of proximities: Multidimensional scaling with an unknown distance function. I. Psychometrika, 27, 125-140.

Shepard, R. N. (1962b). The analysis of proximities: Multidimensional scaling with an unknown distance function. II. Psychometrika, 27, 219-246.

Received August 2, 1983

Revision received December 20, 1983 